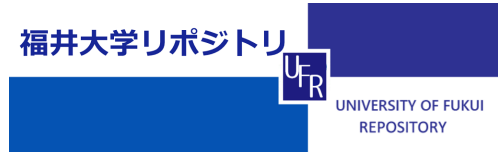

Sl ow scan vol tametry for di ffusi on- cont rol I ed cur rent s i n sodi um al gi nate sol ut i ons

\begin{tabular}{|l|l|}
\hline 著者 & $\begin{array}{l}\text { Wang Bo, Aoki Koi chi Jeremi ah, Chen Ji ngyuan, } \\
\text { N shi um Toy ohi ko }\end{array}$ \\
\hline $\begin{array}{l}\text { j our nal or } \\
\text { publ i cat i on ti tl e }\end{array}$ & Journal of El ect roanal yt i cal Chemi st ry \\
\hline vol ume & 700 \\
\hline page range & $60-64$ \\
\hline year & $2013-04$ \\
\hline URL & ht t p: //hdl . handl e. net /10098/9862 \\
\hline
\end{tabular}




\title{
Slow scan voltammetry for diffusion-controlled currents in sodium alginate solutions
}

Bo Wang, Koichi Jeremiah Aoki", Jingyuan Chen, Toyohiko Nishiumi

Department of Applied Physics, University of Fukui, 3-9-1 Bunkyo, Fukui, 910-0017 Japan

\begin{abstract}
Slow scan voltammetry is useful for extracting Faradaic diffusion-controlled current from capacitive one, because the former and the latter are, respectively, proportional to the square-root of scan rate and the scan rate itself. This report shows clear, reproducible voltammograms of $0.5 \mu \mathrm{M}$ redox species with the help of sodium alginate (SA) at scan rates less than $0.1 \mathrm{mV} \mathrm{s}^{-1}$. SA enhances viscosity of solution without any influence on diffusion coefficient of the redox species so that natural convention is suppressed during the slow scan. Therefore, it allowed us to obtain ideal voltammograms reproducibly at slow scans, retaining the Faradaic current. Especially, a wire electrode is demonstrated to be a powerful tool for detecting low concentrations by slow scan voltammetry because of the large electrode area in comparison with the length of the boundary between the electrode and the insulator. A voltammetric detection limit is obtained in the relationship between the scan rates and concentration of redox species.
\end{abstract}

key words: viscous sodium alginate solutions; slow scan voltammetry; diffusion-controlled currents at cylindrical electrodes; suppression of natural convection

\footnotetext{
* corresponding author, e-mail: kaoki@u-fukui.ac.jp (K.J. Aoki), fax +91 776278750 , phone: +81776278665
} 


\section{Introduction}

Voltammetry at slow scan rates less than $0.1 \mathrm{mV} \mathrm{s}^{-1}$ is useful for exhibiting well-defined redox responses in searching for performance of lithium ion batteries [1]. The voltammetric peak currents were controlled by diffusion of lithium in graphite, as was demonstrated by the proportionality of the currents to square-roots of scan rates [1]. The controlling step was also supported by the Cottrell plot for long-term chronoamperometric responses of reduction of lithium ions [2]. The voltammetric capacitive current is, in contrast, proportional to the scan rate. If observed current is a simple sum of the diffusion-controlled current, $I_{\mathrm{d}}$, and the capacitive one, $I_{\mathrm{c}}$, the ratio, $I_{\mathrm{c}} / I_{\mathrm{d}}$, decreases by 10 times with 100 times decrease in the scan rates. This is a reason for exhibiting the advantage of extremely slow scan voltammetry. A key of obtaining slow scan voltammograms reproducibly is to prevent disturbance from natural convection at a long term measurement. Fortunately, the current by the intercalation is controlled by diffusion of metal atoms into solid anodes [1,3-5] and solid cathodes [6-9], and hence disturbance by convection ought to be suppressed. This advantage has been realized also in voltammetry at film-coated electrodes in a thin layer cell [10-16]. Natural convection may be mechanically suppressed not only with the viscous films but also with the film boundary. Slow scan voltammetry has also been applied to detection of catalytic currents [17-21] at the aim of enhancing catalytic kinetics over mass transport. It has been used for obtaining well-defined voltammograms at low temperatures [22].

In order to apply slow scan voltammetry to general usage without the above limited conditions of electrolysis, it is necessary to avoid unexpected natural convention or mass transport of products generated at a counter electrode to the working electrode. A technique of preventing natural convection is to use viscous solvents [23-31]. An increase in the viscosity decreases generally the diffusion coefficient, according to the Stokes-Einstein equation [32], so that Faradaic currents also decrease. Addition of 
sodium alginate (SA) enhances the viscosity without changing diffusion coefficients of molecules [24,26,33-36]. Molecules may not collide with the network of SA but diffuse through the domain of the aqueous solution [36]. Consequently slow scan voltammetry in SA may exhibit a potentiality of extracting Faradaic currents from capacitive ones.

The other technique of extracting Faradaic currents from background currents is microelectrode voltammetry. Unfortunately, microdisk electrodes are unsuitable for detecting low concentrations of electroactive species because of difficulty in detecting very small current. Microdisk array electrodes and microband electrodes have large surface area. However, they also have long boundaries between the electrode and the insulating wall, which yields large irreproducible capacitive current. It is a long cylindrical or a long wire electrode that shows large currents under quasi steady-state current $[37,38]$. A wire electrode has another advantage of yielding reproducible Faradaic currents, because the boundary between the wire and the insulator which often causes floating capacitive currents is much shorter than the length of the wire $[39,40]$. If wire electrodes are used in SA solution at slow scans, they are expected to show highly sensitive Faradaic currents with negligible effects of natural convention.

This report deals with finding practical conditions of exhibiting diffusion-controlled voltammograms at slow scans in aqueous solutions. Aminoferrocene and hexacyanoferrate are used for redox species in SA solution which suppresses natural convection during long term electrolysis. A disk electrode and a long wire electrode are employed for determining the lowest limit of the concentrations.

\section{Experimental}

Ferrocenyl tetramethylammmonium hexafluorophosphate (FcTMA), was synthesized in house. FcTMA contained salt, mainly ammonium iodide, which was formed when iodide in ferrocenyl tetramethylammmonium iodide was substituted for 
hexafluorophosphate. Accurate concentrations of FcTMA solutions were determined by voltammetric peak for the known value of the diffusion coefficient [41]. Water was deionized and distilled. Potassium hexacyanoferrate(II) was of analytical grade (Wako).

Powder of sodium alginate (Wako) was used as received. The concentration used was $12 \mathrm{~g} \mathrm{~cm}^{-3}$, corresponding to $43 \mathrm{mPa}$. It was chosen simply because of easy mixing and deaeration. It was dissolved in distilled water at $60^{\circ} \mathrm{C}$ to yield homogeneous solution. Air bubbles coming from the powder were removed by ultrasonication for 30 $\min$.

Cyclic voltammetry was carried out with a potentiostat, Compactstat (Ivium Tech., Netherlands), in viscous mixtures. A platinum disk $1.6 \mathrm{~mm}$ in diameter and a platinum wire $0.1 \mathrm{~mm}$ in diameter were used as voltammetric working electrodes. The reference electrode was $\mathrm{Ag} \mid \mathrm{AgCl}$ in saturated $\mathrm{KCl}$. The counter electrode was a platinum wire. Viscosity was determined with a vibration viscometer, SV-10 (A\&D, Tokyo), at room temperature.

\section{Results and Discussion}

Figure 1 shows linear sweep voltammograms of $\mathrm{Fe}(\mathrm{CN})_{6}{ }^{4-}$ in $\mathrm{KCl}$ solution (A) without and (B) with SA at the platinum electrode $1.6 \mathrm{~mm}$ in diameter at low scan rates. Voltammograms at scan rates, $v$, over $5 \mathrm{mV} \mathrm{s}^{-1}$ exhibited conventional, peaked currents (not shown), similar to those in Fig. 1(B). Voltammograms of FcTMA were close to those in Fig. 1 except for peak potentials and the sign of waves. Voltammograms of both $\mathrm{Fe}(\mathrm{CN})_{6}{ }^{4-}$ and FcTMA without SA showed complicatedly wave-like variations at $v<0.5$ $\mathrm{mV} \mathrm{s}^{-1}$ (Fig. 1(A)). The complication is probably due to natural convection. When SA was added to the solution so that the viscosity increased by 50 times, the voltammetric currents were slightly smaller than those without SA. According to Randles-Sevcik's equation, the decrease in the diffusion coefficient by 50 times should decrease the peak 
current by 7 times. The small difference in the peak currents with and without SA has been explained in terms of the easy permeation of redox species through the network structure of SA [36]. Since SA molecules include carboxylic groups, they may form complexes with cations, as for silver ion [36]. No complication for FcTMA was found, for example, precipitation and shift of the oxidation potential. No redox reaction of SA was found in the SA solution without redox species, as shown by the dashed curve in Fig. 1B.

Figure 2 shows dependence of the peak currents of FcTMA and $\mathrm{Fe}(\mathrm{CN}) 6^{4-}$ with (triangles) and without (circles) SA on $v^{1 / 2}$. The peak currents with SA for $v>3 \mathrm{mV} \mathrm{s}^{-1}$ were almost the same as those without SA, whereas those with SA for $v<1 \mathrm{mV} \mathrm{s}^{-1}$ were smaller than those without SA. The ratio of the peak currents with $\mathrm{SA},\left|I_{\mathrm{p}}\right| \mathrm{SA}$, to that without SA, $I_{\mathrm{p}}$, is plotted against $v^{1 / 2}$ on the right ordinate in Fig. 2. The deviation of $I_{\mathrm{p}} /\left|I_{\mathrm{p}}\right| \mathrm{SA}$ from unity increases with a decrease in the scan rates. The increase must be due to natural convection by taking into account of Fig. 1(A). The fact of $\left|I_{\mathrm{p}}\right| \mathrm{SA}=I_{\mathrm{p}}$ for $v>3$ $\mathrm{mV} \mathrm{s}^{-1}$ suggests no adsorption of SA on the electrode.

The currents in SA solutions for $v>3 \mathrm{mV} \mathrm{s}^{-1}$ in Fig. 2 were accurately proportional to $v^{1 / 2}$, whereas those for $v<3 \mathrm{mV} \mathrm{s}^{-1}$ deviated from the proportionality. The deviation is ascribed to the edge effect of diffusion [42], because the peak current for small values of $a(F v / R T D)^{1 / 2}$ is approximated as

$$
I_{\mathrm{p}} \approx 0.446 A F c^{*} \sqrt{F D v / R T}+2.1 F c^{*} D a
$$

where $a$ is the radius of the disk electrode and $D$ is the diffusion coefficient of the electroactive species. Therefore, slow scan voltammograms include currents with the edge effect of diffusion even at a large disk electrode. The voltammograms without SA deviate from the proportionality for $v<5 \mathrm{mV} \mathrm{s}^{-1}$ more largely than those with SA.

The platinum wire $0.1 \mathrm{~mm}$ in diameter and $10 \mathrm{~mm}$ in length was used as a working electrode. The length was the immersing distance rather than that provided by an 
insulator. The wave form of linear sweep voltammograms was sigmoid at low scan rates, and had peaked shape at fast scans. The voltammograms of FcTMA without SA at $v<1$ $\mathrm{mV} \mathrm{s}^{-1}$ contained irregular waves or noises, as shown in Fig. 3(a). In contrast, a voltammogram with SA showed a smooth curve with a vague peak (Fig. 3(b)). The peak currents or the limiting currents with SA were larger than those without SA.

Peak currents or limiting currents, $I_{\mathrm{L}}$, for $\mathrm{Fe}(\mathrm{CN})_{6}{ }^{4-}\left(I_{\mathrm{L}}<0\right)$ and FcTMA $\left(I_{\mathrm{L}}>0\right)$ were obtained at various scan rates, and were plotted against $v^{1 / 2}$ in Fig. 4 . The currents with SA had a linear relationship with $v^{1 / 2}$ rather than a proportional relation. Appearance of the intercept can be predicted from the theoretical expression for cylindrical diffusion [43]. The current ratio for $v<50 \mathrm{mV} \mathrm{s}^{-1}$, plotted on the right ordinate in Fig. 4, was larger than unity. The ratio of the currents for $v>20 \mathrm{mV} \mathrm{s}^{-1}$ in Fig. 4 (the wire) is larger than that in Fig. 2 (the disk). Wire electrodes are more strongly affected by natural convection than disk electrodes at slow scans. Noiseless voltammograms in SA solution (in Fig. 3(b)) indicates that SA suppresses convection at wire electrodes.

In order to see fluctuation of the current by natural convection, we made long-term chronoamperometry at $0.55 \mathrm{~V}$ for FcTMA and $0.15 \mathrm{~V}$ for $\mathrm{Fe}(\mathrm{CN})_{6}^{4-}$. Figure 5 shows chronoamperometric curves at the (A) disk and (B) wire electrode in solutions (a, c) with and $(\mathrm{b}, \mathrm{d})$ without SA, where $I>0$ is for FcTMA and $I<0$ is for $\mathrm{Fe}(\mathrm{CN})_{6}{ }^{4-}$. Three current-time curves with SA $(\mathrm{a}, \mathrm{c})$ were overlapped each other. Curves without SA varied from run to run at times over $10 \mathrm{~s}$, and their currents, $|I|$, were larger than $|I|_{\mathrm{SA}}$. Irreproducibility of the currents at the wire electrode (B) was noticeable earlier than that at the disk electrode (A).

Slow scan voltammetry in the SA solution is expected to discern low concentrations of electroactive species from capacitive currents. We obtained voltammograms of $1 \mu \mathrm{M}$ FcTMA at various slow scan rates, as shown in Fig. 6 (A) without and (B) with SA. When solution contained SA, the faradaic waves were 
obtained clearly and reproducibly even at $v=0.01 \mathrm{mV} \mathrm{s}^{-1}$. The background-corrected limiting currents of $1 \mu \mathrm{M}$ FcTMA in the SA solution are plotted against $v^{1 / 2}$ in Fig. 7. Fluctuation was small enough for determining the limiting currents. The linear dependence of the current on $v^{1 / 2}$ was close to that in Fig. 4.

Analytical significance of voltammograms is not only well-defined, reproducible waveform but also proportionality of the current to concentration. We examined whether limiting currents of background-corrected, reproducible voltammograms were proportional to concentrations at several scan rates. The limiting currents are plotted against concentrations of FcTMA for two scan rates in Fig. 8, where slopes of the solid lines are unity. The lowest concentration at $v=100 \mathrm{mV} \mathrm{s}^{-1}$ in the viewpoints of background correction and reproducibility was $0.01 \mathrm{mM}$, regardless of the presence or the absence of SA. Experimental values fell on a dashed line with a slope smaller than unity (in Fig. 8), probably because of a contribution of capacitive currents at low concentrations. In contrast, the slow scan of $0.1 \mathrm{mV} \mathrm{s}^{-1}$ allowed us to obtain the reliable limiting current up to $1 \mu \mathrm{M}$ without SA. When solutions contained SA, the readily available lowest concentration was $0.5 \mu \mathrm{M}$.

\section{Conclusions}

Slow scan voltammetry is quantitatively demonstrated to discern diffusion-controlled current from capacitive one. The reason of the successful discrimination is the difference in scan rate dependence of the two currents. Slow scan voltammograms are necessarily complicated by uncontrollable natural convention. The convection can be suppressed with addition of SA, which decreases viscosity tremendously but does not alter diffusion coefficients of redox species. Therefore voltammograms can be obtained reproducibly without blocking redox reactions. Slow 
scan voltammetry can be used as a conventionally electrochemical tool if SA is added to solution.

Slow scan voltammetry is suitable for detection of redox species with low concentrations. Recommended electrodes for this purpose are wire electrodes without shielding by insulating wall, because shielding is a source of large and irreproducible capacitive currents. Although a wire electrode is normally unsuitable for long electrolysis owing to fluctuation by convection, addition of SA to solutions can keep quasi-state state currents reproducible. Voltammetry for $v=0.1 \mathrm{mV} \mathrm{s}^{-1}$ at a wire electrode in SA solution allows us to determine concentrations up to $0.5 \mu \mathrm{M}$ without specific instrumentation. However, long time is consumed. As a conclusion, an advantage of the present technique is determination of concentration without effects of adsorption of redox species and capacitive currents because of long time electrolysis.

\section{References}

[1] M.D. Levi, D. Aurbach, J. Electroanal. Chem. 421 (1997) 79.

[2] M.D. Levi, E.A. Levi, D. Aurbach, J. Electroanal. Chem. 421 (1997) 89.

[3] M. Minakshi, Electrochim. Acta 55 (2010) 9174.

[4] T. Ohzuku, Y. Iwakoshi, K. Sawai J. Electrochem. Soc. 140 (1993) 2490.

[5] F. Nobili, S. Dsoke, M. Mancini, R. Tossici, R. Marassi, J. Power Sources 180 (2008) 845 .

[6] J.-H. Kim, K. Zhu, J. Y. Kim, A. J. Frank, Electrochim. Acta 88 (2013) 123.

[7] Z. Lu, M.D. Levi, G. Salitra, Y. Gofer, E. Levi, D. Aurbach, J. Electroanal. Chem. $491(2000) 211$.

[8] M. Liberatore, F. Decker, A. S. Vuk, B. Orel, G. Drazic, Solar Energy Mat. 90 (2006) 434. 
[9] K.M. Begam, Y.H. Taufiq-Yap, M.S. Michael, S.R.S. Prabaharan, Solid State Ionics $172(2004) 47$.

[10] C. Shi, F. C. Anson, Anal. Chem. 70 (1998) 3114.

[11] C. Shi, F. C. Anson, J. Phys. Chem. B 103 (1999) 6283.

[12] M. Liberatore, A. Petrocco, F. Caprioli, C. La Mesa, F. Decker, C.A. Bignozzi, Electrochim. Acta 55 (2010) 4025.

[13] T.D. Chung, J. Kor. Electrochem. Soc. 5 (2002) 216.

[14] F. Quentel, V. Mirceski, M. L'Her, F. Spasovski, M. Gacina, Electrochem. Commn. 9 (2007) 2489.

[15] V. Mirceski, R. Gulaboski, I. Bogeski, M. Hoth, J. Phys. Chem. C 111 (200) 6068.

[16] X. Liu, L. Hu, L. Zhang, H. Liu, X. Lu, Electrochim. Acta 51 (2005) 467.

[17] F. Maillard, M. Martin, F. Gloaguen, J.-M. Leger, Electrochim. Acta 47 (2002) 3431.

[18] Y. Liu, S. Mitsushima, K. Ota, N. Kamiya, Electrochim. Acta 51 (2006) 6503.

[19] F. Seland, R. Tunold, D. A. Harrington, Electrochim. Acta 55 (2010) 3384.

[20] M. Yagi, K. Nagai, T. Onikubo, M. Kaneko, J. Electroanal. Chem. 383 (1995) 61.

[21] A.D. Modestov, M.R. Tarasevich, H. Pu, J. Power Sources 205 (2012) 207.

[22] M. Opallo, J. Electroanal. Chem. 411 (1996) 145.

[23] C.-C. Wu, H.-N. Luk, Y.-T. T. Lin, C.-Y. Yuan, Talanta 81 (2010) 228.

[24] A. Kikuchi, M. Kawabuchi, A. Watanabe, M. Sugihara, Y. Sakurai, T. Okano, J.

Control. Rel. 58 (1999) 21.

[25] G. Zhao, X. Zhan, W. Dou, Anal. Biochem. 408 (2011) 53.

[26] A.C.F. Ribeiro, A.J.F.N. Sobral, S.M.N. Simoes, M.C.F. Barros, V.M.M. Lobo, A.

M.T.D.P.V. Cabral, F.J.B. Veiga, C.I.A.V. Santos, M.A. Esteso, Food Chem. 125 (2011) 1213.

[27] K. Aoki, Y. Guo, J. Chen, J. Electroanal. Chem, 629 (2009) 73. 
[28] Y. Guo, K. Aoki, J. Chen, T. Nishiumi, Electrochem. Acta, 56 (2011) 3727.

[29] J. Legrand, E. Dumont, J. Comiti, F. Fayolle, Electrochim. Acta 45 (2000) 1791.

[30] R. D. Tonini, M. R. Remorino, F. M. Brea, Electrochim. Acta, 23 (1978) 699.

[31] J. van der Gucht, N. A. M. Besseling, H. P. van Leeuwen, J. Phys. Chem. B 108 (2004) 2531 .

[32] P.W. Atkins, Physical Chemistry, Sixth edition, Oxford University Press, Oxford, 1998, pp. 690-691.

[33] M. Grassi, I. Colombo, R. Lapasin, J. Control. Rel. 76 (2001) 93.

[34] W. Lubas, P. Ander, Macromolecules 13 (1980) 318.

[35] Y. Li, X. Zhao, Q. Xu, Q. Zhang, D. Chen, Langmuir 27 (2011) 6458.

[36] K. Aoki, B. Wang, J. Chen, T. Nishiumi, Electrochim. Acta, 83 (2012) 348.

[37] K. Aoki, K. Honda, K. Tokuda, H. Matsuda, J. Electroanal. Chem. 182 (1985) 267.

[38] K. Aoki, Electroanalysis 5 (1993) 627.

[39] K. Aoki, Y. Hou, J. Chen, T. Nishiumi, J. Electroanal. Chem. 689 (2013) 124.

[40] K. Aoki, X. Zhao, J. Chen, T. Nishiumi, J. Electroanal. Chem. submitted.

[41] H. Zhang, K. Aoki, J. Chen, T. Nishiumi, H. Toda, E. Torita, Electroanalysis, 23 (2011) 947.

[42] K. Aoki, K. Akimoto, K. Tokuda, H. Matsuda, J. Osteryoung, J. Electroanal. Chem. $171(1984) 219$.

[43] K. Aoki, K. Aikimoto, K. Tokuda, H. Matsuda, J. Osteryoung, J. Electroanal. Chem. $182(1985) 267$. 